Currículo sem Fronteiras, v. 19, n. 3, p. 1243-1263, set./dez. 2019

\title{
A LUTA PELA INSERÇÃO DA DISCIPLINA DE SOCIOLOGIA NA EDUCAÇÃO BÁSICA NO BRASIL E AS ESPECIFICIDADES DA EDUCAÇÃO DE JOVENS E ADULTOS
}

\author{
Edgar Gomes Júnior \\ Instituto Federal de Educação, Ciência e Tecnologia do Norte de Minas Gerais - IFNMG \\ Gilvanice Barbosa da Silva Musial \\ Universidade Federal da Bahia - UFBA
}

\begin{abstract}
Resumo
Esse artigo apresenta alguns resultados de uma pesquisa desenvolvida no Mestrado em Educação e tem como objetivo analisar os desafios para a inserção da disciplina Sociologia na Educação de Jovens e Adultos em Minas Gerais. No momento em que a educação sofre os ataques dos setores conservadores da sociedade que propõe a retirada de disciplinas como filosofia e sociologia dos currículos escolares, faz-se necessário lembrar a luta pela inserção da Sociologia na Educação básica brasileira. Do ponto de vista teórico-metodológico, trabalhamos com André Chervel (1990) para a história das disciplinas escolares, Bourdieu (2006, 2014) para a noção de campo e Apple (2006), Sacristán (2000) e Arroyo (2013), para a discussão sobre currículo. Trata-se de uma pesquisa bibliográfica e documental. Como resultados, indicamos que, sendo o currículo um campo de disputa, a disciplina de Sociologia tem ocupado um lugar provisório, questionado em alguns momentos político-sociais e defendido em outros. Quanto ao ensino de Sociologia na Educação de Jovens e Adultos, esse enfrenta um duplo desafio, estabelecer-se como campo legítimo em um espaço que também ocupa lugar marginal e transitório nas Políticas Educacionais.
\end{abstract}

Palavras-chave: Currículo, Disciplina de Sociologia, Educação de Jovens e Adultos.

\begin{abstract}
This article presents some results of a research developed in the Masters in Education and aims to analyze the challenges for the insertion of the discipline Sociology in the Education of Young and Adults in Minas Gerais. At a time when education is being attacked by the conservative sectors of society that propose the withdrawal of disciplines such as philosophy and sociology from school curriculum, it is necessary to remember the struggle for the insertion of Sociology into Brazilian Basic Education. From a theoretical and methodological point of view, we work with André Chervel (1990) for the history of school subjects, Bourdieu $(2006,2014)$ for the notion of Campo e Apple (2006), Sacristán (2000) and Arroyo (2013) a discussion on curriculum. This is a bibliographical and documentary research. As results, we indicate that, since the curriculum is a field of contention, the discipline of sociology has occupied a provisional place, questioned in political and social moments and defended in others. As for the teaching of Sociology in Youth and Adult Education, it faces a double challenge, establishing itself as a legitimate field in a field that also occupies a marginal and transitory place in Educational Policies.
\end{abstract}

ISSN 1645-1384 (online) www.curriculosemfronteiras.org

http://dx.doi.org/10.35786/1645-1384.v19.n3.26 
Keywords: Discipline of Sociology, Youth and Adult Education, Curriculum.

\section{Introdução}

O presente artigo apresenta parte dos resultados de uma pesquisa realizada no Mestrado em Educação da UEMG sobre o ensino de Sociologia na Educação de Jovens na rede estadual de educação do Estado de Minas Gerais. Ele pretende apresentar elementos para a compreensão da inserção e manutenção da disciplina de Sociologia na referida modalidade da Educação básica que tem sido, historicamente, um campo secundarizado nas políticas educacionais brasileiras. Por trazer essa temática, não podemos deixar de mencionar a recente conjuntura política do país que, após o impedimento (impeachment) ${ }^{1}$ da presidente Dilma Rousseff $^{2}$ e a efetivação do vice-presidente da república, Michel Temer, do Partido do Movimento Democrático Brasileiro - PMDB, na Presidência da República e, posteriormente, a eleição de Jair Bolsonaro do Partido Social Liberal - PSL produziu ${ }^{3}$ mudanças significativas no direcionamento no projeto de desenvolvimento que vinha sendo executado e, especialmente, nos programas e políticas educacionais.

Uma das mudanças trazidas no contexto da educação básica brasileira foi a reforma do ensino médio que ocorreu em 2016. Ela foi aprovada por Medida Provisória - MP n.746 e foi convertida na Lei Federal $n^{\circ} .13 .415$, de 16 de fevereiro de $2017^{4}$. Analisando o texto dessa lei, percebemos que foi suprimida a obrigatoriedade no ensino médio das disciplinas de Filosofia e Sociologia, conforme constava no Inciso IV do art. 36 da Lei de Diretrizes e Bases da Educação, inciso este inserido pela Lei Federal $n^{\circ} 11.684 / 2008$. No lugar, a nova lei 13.415/2017 trouxe o seguinte trecho, no $2^{\circ}$ parágrafo do art. $3^{\circ}$ : “A Base Nacional Comum Curricular (BNCC) referente ao ensino médio incluirá obrigatoriamente estudos e práticas de educação física, arte, sociologia e filosofia”. (BRASIL, 2017).

Considera-se que existe uma diferença substancial, entre os termos incluir estudos e práticas na BNCC e a obrigatoriedade das disciplinas Sociologia e Filosofia no currículo do Ensino Médio, trazida anteriormente pela Lei $N^{\circ} 11.684 / 2008$ que alterava a LDB n 9394 de 1996. Considera-se, ainda, que essas mudanças visam “flexibilizar” o currículo, de modo a não garantir a presença das disciplinas no currículo do Ensino Médio, nem de docentes com formação nessas áreas, como foi vivenciado anteriormente (AMURABI, 2011; FERNANDES; PONTE JARDIM, 2008).

Considerando o cenário mais recente, já sob o governo do Presidente Jair Bolsonaro, a comunidade acadêmica tem sido surpreendida com declarações dos Ministros da Educação Ricardo Vélez, e do atual Abraham Weintraub, que questionam não apenas a importância e a necessidade da oferta dos cursos nas áreas das disciplinas Sociologia e Filosofia para a Educação básica, bem como a relevância das Ciências Humanas para formação das novas gerações. Por outro lado, propõe uma educação mais prática e direcionada para o mercado do trabalho.

Do ponto de vista teórico-metodológico, esse texto é fruto de uma pesquisa bibliográfica e documental, de abordagem qualitativa. Foram analisadas legislações do sistema estadual de educação de Minas Gerais, no período de cinco anos (2012-2016), devido às mudanças nas decisões sobre o modo de funcionamento da EJA, emanadas da SEE-MG, por meio de 
resoluções e de ofícios circulares do órgão. Mobilizamos as formulações de André Chervel (1990) para uma análise sobre a história das disciplinas escolares, de Bourdieu (2006 e 2014) para a utilização do conceito de campo e de Apple (2006), Sacristán (2000) e Arroyo (2013) para a discussão sobre currículo em uma perspectiva crítica.

Esse artigo está dividido da seguinte forma: além dessa introdução, no segundo tópico, apresentamos um breve histórico da luta pela inserção da disciplina de Sociologia na Educação Básica, em seguida dialogamos com discussões teóricas sobre o conceito de campo, sobre a história das disciplinas e de currículo, no terceiro, analisamos a Educação de Jovens e Adultos como um campo secundarizado nas políticas educacionais brasileiras, no quarto, fazemos uma análise sobre a institucionalização da EJA presencial na Rede de Educação do Estado de Minas Gerais e a inserção da disciplina Sociologia na referida modalidade. Finalmente, indicamos que, sendo o currículo um campo de disputa, a disciplina de Sociologia tem ocupado um lugar provisório, questionado em alguns momentos políticosociais e defendido em outros, o que impõe a educadores comprometidos com uma educação transformadora, uma constante luta e vigilância em prol da permanência desse campo do conhecimento nos currículos escolares no país.

\section{Breve histórico da luta pela inserção da disciplina de Sociologia na Educação Básica}

O marco considerado como início da história do ensino de Sociologia no Brasil é 1891, quando da passagem de Benjamim Constant como Ministro da Instrução Pública do Governo de Deodoro da Fonseca. Porém, Moraes (2011) chama a atenção que essa inclusão se tratava de um fato restrito ao Colégio Pedro II, na capital da recém criada República, a cidade Rio de Janeiro - RJ. Outro aspecto a ser observado é o modo como a educação brasileira estava organizada, descentralizada de tal forma que cada Estado produzia sua própria legislação, sendo que somente nas décadas de 1920/30 inicia-se o processo de centralização da educação.

Um segundo marco é a Reforma Rocha Vaz, que com o Decreto n. 16.782-A, de 13/01/1925, torna a Sociologia obrigatória nos anos finais dos cursos preparatórios. Moraes (2011) elenca que:

é necessário dizer que esse espraiamento do ensino de Sociologia ocorreu na ausência de cursos de formação de professores de Sociologia, sendo comum a presença de advogados, médicos e engenheiros para cobrir essa carência. É interessante também notar que essa Reforma (1925), que, entre outras providências, institui a obrigatoriedade do ensino de Sociologia na escola secundária de então cursos preparatórios e complementares -, foi concebida durante o governo talvez mais autoritário da chamada República Velha, o de Arthur Bernardes (MORAES, 2011, p. 362).

Posteriormente, outro marco consensual foi a Reforma Capanema do ano de 1942, ainda no governo do Presidente Getúlio Vargas, que, através do Decreto n. 4.244/1942, marca o 
fim da obrigatoriedade do ensino de Sociologia na escola secundária. Essa Reforma reorganizou a educação brasileira, em especial, redefinindo o ensino secundário, em dois segmentos, ginasial (4 anos) e colegial (3 anos), sendo que este último apresentava-se em dois formatos opcionais para os alunos: clássico e científico, ambos concebidos como preparatórios para o ensino superior e voltados para a "formação das individualidades condutoras"” (ROMANELLI, 1995, p.158).

Segundo Meucci (2000), pode-se considerar que esses movimentos de idas e vindas da disciplina de Sociologia na educação básica brasileira estiveram atrelados à noção de projeto de Brasil, vinculado à ideia de progresso, civismo e de conhecimento e compreensão da realidade nacional para o desenvolvimento da nação, principalmente após 1930. A expectativa que se tinha para a disciplina de Sociologia, principalmente nas suas primeiras décadas, era dela ser um conteúdo mais conservador, para desenvolver essa noção de civismo, de sentimento de pertencimento à pátria.

Após mais de 13 anos de tramitação, foi aprovada a primeira Lei de Diretrizes e Bases da Educação Nacional - LDB, n. 4024/1961. Porém, mesmo em um período mais aberto aos debates educacionais, a disciplina de Sociologia permaneceu fora dos currículos oficiais. Nesse ponto, Moraes (2011) questiona a tese de que a permanência e a exclusão da disciplina de Sociologia na história da educação brasileira esteve atrelada à presença ou não de governos autoritários. Na opinião do autor, o fato se deveu muito mais à incapacidade da disciplina se estabelecer, trazendo metodologias, conteúdos e formas de instituir suas teorias no processo educativo como um todo. Para ele, esse versão da história da disciplina, na qual ela tenha sofrido certa "perseguição" dos governos autoritários foi utilizada como forma de fortalecer o discurso para tornar a disciplina obrigatória no sistema educacional.

Em 1971, ocorreu uma nova reforma na educação Brasileira com a Lei n. 5692. Nela, a Sociologia que já não era obrigatória, permanece ausente dos currículos da escola secundária junto com a Filosofia. Aparece nessa Lei a obrigatoriedade das disciplinas Educação Moral e Cívica e Organização Social e Política Brasileira.

No final da Ditadura civil-militar, no início dos anos 1980, a defesa da inserção da disciplina Sociologia no ensino secundário volta a ganhar força. Primeiro no Estado de São Paulo, onde a Secretaria de Estado da Educação - SEE, pela Resolução SEE/SP n 236/83, recomenda a disciplina em seus currículos. Segundo Moraes (2011), esse fato passa a legitimar a luta pela inserção da disciplina, de tal modo que outros Estados vão acompanhar São Paulo. Essa luta pela inclusão da disciplina de Sociologia permanecerá de forma heterogênea em cada Estado até a promulgação da LDB nº 9394 de 1996, que estabelece a inclusão dos conteúdos de Sociologia e Filosofia no currículo da Educação Básica.

Entretanto, da forma como foi descrita na Lei, essa inserção será alvo de disputa. O Parecer do Conselho Nacional de Educação interpreta-a afirmando que não havia a obrigatoriedade da presença das disciplinas de Sociologia e Filosofia nos currículos da Educação Básica, de modo que os conteúdos previstos poderiam ser trabalhados pelas disciplinas Geografia e História.

Com o objetivo de dar continuidade à luta pela introdução das duas disciplinas no currículo da Educação Básica, o então deputado Federal Padre Roque Zimmerman (PT-PR) 
inicia a tramitação do Projeto de Lei n 3178 de 1997, solicitando mudança no texto da LDB de 1996, tornando-o explícito quanto à necessidade das disciplinas de Filosofia e Sociologia adquirirem caráter obrigatório no currículo do Ensino Médio. A Lei é aprovada em setembro de 2001 no Congresso Nacional, porém é vetada no mês seguinte pelo então Presidente, o sociólogo Fernando Henrique Cardoso, que alega falta de estrutura por não terem docentes formados nessas áreas em número suficiente, além da possibilidade de aumento dos custos dos Estados para essas respectivas contratações.

Todavia, a disciplina de Sociologia já estava presente nos currículos de vários Estados, fato que a luta pela obrigatoriedade começa a ganhar cada vez mais corpo pelos sindicatos das categorias, pelas Associações de Pesquisa da área, como na Sociedade Brasileira de Sociologia, na qual cada vez mais os especialistas são convidados para discutir os documentos orientadores para aplicação do currículo pelo Ministério da Educação no início da década de 2000. Houve, de certa forma, uma mudança de estratégia dos atores envolvidos na luta pela obrigatoriedade das disciplinas de Sociologia e Filosofia, pressionando o Conselho Nacional de Educação a realizar audiências para emitir um parecer sobre a situação dessas áreas:

Assim, a aprovação, ao fim e ao cabo, do Parecer n. 38/2006, pelo CNE, determinando o tratamento disciplinar e obrigatório para Sociologia em escolas com currículo estruturado por disciplinas, acabou contribuindo para uma maior legitimação de sua presença nos currículos (MORAES, 2011, p. 376).

Antes da promulgação da Lei 11.684/2008, os conteúdos relacionados diretamente à disciplina de Sociologia já estavam estabelecidos nos Parâmetros Curriculares Nacionais para o Ensino Médio - PCNEM, porém, como lembram Fernandes e Ponte Jardim (2008), esse movimento ${ }^{5}$ passou a tomar contornos nacionais desde a década de 1990, ou seja,

a partir da promulgação da atual Lei de Diretrizes e Bases da Educação Nacional, a Lei 9394/96, dos Parâmetros Curriculares Nacionais e as Diretrizes Curriculares Nacionais para o Ensino Médio (DCNEM) e do Parecer 15/98 do Conselho Nacional de Educação. Em conjunto, essa legislação reestruturou o Ensino Médio, particularmente na área das Ciências Humanas, estabelecendo os conceitos, os procedimentos e as atitudes provenientes da Geografia, História, Filosofia e da Sociologia que passaram a constituir a área de Ciências Humanas e suas Tecnologias (FERNANDES; PONTE JARDIM, 2008, p.10).

Os autores acima reconhecem também que houve um processo de "lentidão e incongruências” nesse processo que exigiu dos envolvidos, docentes e estudantes de Ciências Sociais, que concentrassem esforços para intervenções no Ministério da Educação cuja junção com a luta pela inserção da disciplina de Filosofia, também em nível nacional, fortalecesse o processo de retorno de ambas as disciplinas como obrigatórias no currículo da Educação Básica do país, após uma “trajetória conturbada” (FERNANDES; PONTE 
JARDIM, 2008, p. 11). Salientam que a inclusão da disciplina de Sociologia nas várias redes estaduais e municipais de ensino adquiriu contornos e tempos variados:

Em suma, a luta pela volta da Sociologia ocorreu de diferentes maneiras com estratégias distintas: por lei estadual e agora federal, por via administrativa (quando a Secretaria de Educação decide a questão), por via dos vestibulares, pela mobilização dos cursos em suas regiões. Há casos de municípios e escolas que introduziram a disciplina no Ensino Fundamental e no Ensino Supletivo (FERNANDES; PONTE JARDIM, 2008, p.11).

A partir do parecer n. 15 de 1998 do Conselho Nacional de Educação, continuaram as movimentações que culminaram na recente inclusão da disciplina de Sociologia e Filosofia nos três anos do ensino médio, tornando-as obrigatórias pela Lei 11.684, de 2 de junho de 2008, modificando o inciso IV do artigo 36, da Lei de Diretrizes e Bases (LDB 9394/96).

Esse fenômeno não foi diferente na Rede de Educação do Estado de Minas Gerais REE-MG que, além de inserir a referida disciplina no currículo do Ensino Médio, também normatizou a oferta na Educação de Jovens e Adultos presencial, ampliando a oferta nas escolas básicas, objeto dessa investigação.

\section{A afirmação da disciplina de Sociologia no sistema educacional: dialogando com os conceitos de campo, disciplina e currículo}

Para analisarmos a inserção da disciplina de Sociologia, mobilizamos o conceito de campo a partir Pierre Bourdieu (2006), por entender que tanto a inserção e a permanência da disciplina de Sociologia nos currículos oficiais, como as políticas públicas de efetivação da modalidade da EJA, comportam-se como espaços de disputa em nossa sociedade, onde os agentes envolvidos estão em constantes embates. Para o referido autor:

todas as sociedades se apresentam como espaços sociais, isto é, estruturas de diferenças que não podemos compreender verdadeiramente a não ser construindo o princípio gerador que funda essas diferenças na objetividade. Princípio que é o da estrutura da distribuição das formas de poder ou dos tipos de capital eficientes no universo social considerado - e que variam, portanto, de acordo com os lugares e os momentos. Essa estrutura não e imutável e a topologia que descreve um estado de posições sociais permite fundar uma análise dinâmica da conservação e da transformação da estrutura da distribuição das propriedades ativas e, assim, do espaço social. É isso que acredito expressar quando descrevo o espaço social global 
como um campo, isto é, ao mesmo tempo, como um campo de forças, cuja necessidade se impõe aos agentes que nele se encontram envolvidos, e como um campo de lutas, no interior do qual os agentes se enfrentam, com meios e fins diferenciados conforme sua posição na estrutura do campo de forças, contribuindo assim para a conservação ou a transformação de sua estrutura (BOURDIEU, 2006, p. 47-48).

Dessa forma, fica definido de modo mais amplo o mecanismo fundador do campo como um processo que funciona nas estruturas de todas as sociedades, das mais diversas formas de disputas de poder, de forma articulada, entre os agentes. Posteriormente, o autor apresenta alguns exemplos:

Algo como uma classe ou, de modo mais geral, um grupo mobilizado para e pela defesa de seus interesses, não pode existir senão ao preço e ao termo de um trabalho coletivo de construção inseparavelmente teórico e prático; mas nem todos os agrupamentos sociais são igualmente prováveis e esse artefato social que é sempre um grupo social tem tanto mais oportunidades de existir e subsistir de maneira durável quanto mais os agentes que se agrupam para constitui-lo já estejam mais próximos no espaço social ( $\mathrm{O}$ que vale também para uma unidade fundada sobre uma reação afetiva, amorosa ou amistosa, seja ela ou não socialmente sancionada) (BOURDIEU, 2006, p. 47-48).

Como discutido anteriormente, a história da disciplina de Sociologia tem sido marcada por idas e vindas no sistema educacional brasileiro ao longo da sua existência, como já pesquisado por Meucci (2000), Silva (2006), Moraes (2011) e Fernandes e Ponte Jardim (2006). Chervel (1990) abordou, em uma perspectiva histórica, as construções de sentidos atribuídos ao termo disciplina. A ideia de disciplina escolar, da forma que a conhecemos, surgiu em meados do século XIX:

Na realidade, essa nova acepção da palavra é trazida por uma larga corrente de pensamento pedagógico que se manifesta, na segunda metade do século XIX, em estreita ligação com a renovação das finalidades do ensino secundário e do ensino primário. Ela faz par com o verbo disciplinar, e se propaga primeiro como um sinônimo de ginástica intelectual, novo conceito recentemente introduzido no debate. É durante a década de 1850, que marca o começo da crise dos estudos clássicos, que os partidários das línguas antigas começam a defender a ideia de que, na falta de uma cultura, o latim traz ao menos uma "ginástica intelectual", indispensável ao homem cultivado. [...] Logo após a I Guerra Mundial, enfim, o termo "disciplina" vai perder a força que o caracterizava até então. Toma-se uma pura e simples rubrica que classifica as matérias de ensino, fora de qualquer referência às exigências da formação do espírito (CHERVEL, 1990, p. 3-5, grifo do autor). 
Outro ponto importante, na constituição dos sistemas de ensino e nas sociedades nas quais estão inseridas, as disciplinas passam por um processo de afirmação dentro da cultura escolar, que depende de um tempo de maturação, assim como dos seus efeitos produzidos ao longo de um período. Assim,

Os processos de instauração e de funcionamento de uma disciplina se caracterizam por sua precaução, por sua lentidão, e por sua segurança. A estabilidade da disciplina assim constituída não é então, como se pensa seguidamente, um efeito da rotina, do imobilismo, dos pesos e das inércias inerentes à instituição. Resulta de um amplo ajuste que pôs em comum uma experiência pedagógica considerável; [...]. Ela se prevalece dos sucessos alcançados na formação dos alunos, assim como de sua eficácia na execução das finalidades impostas (CHERVEL, 1990, p. 26).

Ainda sobre o processo de afirmação das disciplinas, esse autor traz uma constatação sobre a ideia dos efeitos produzidos pela disciplina, sentidos pelas gerações anteriores, como segue:

Quando uma disciplina, que não era dispensada até então, se instala solidamente na instituição, quando ela produziu seus efeitos sobre uma geração inteira de alunos, por vinte ou trinta anos ao menos, ela é forçosamente recolocada em questão por seu próprio sucesso. Sua existência continuada não é automática, como se poderia ser tentado a crer. Pois, ao término desse período probatório, ela se dirige a partir de então às crianças ou aos adolescentes cujos pais e o meio familiar receberam uma aculturação que fazia falta totalmente às famílias dos alunos de trinta anos antes (CHERVEL, 1990, p. 50).

A partir das considerações de Chervel (1990), podemos levantar hipóteses de que a disciplina de Sociologia, por sua instabilidade no sistema educacional brasileiro, venha sendo prejudicada na sua possibilidade de produção de efeitos. Um dos resultados dessa instabilidade é a não ampliação efetiva do quadro de docentes com formação específica para lecionarem a disciplina de Sociologia na Educação Básica, contribuindo para uma situação de improvisação e precariedade da mesma nos currículos escolares.

Dados recentes sobre um balanço dos 10 anos desde a inserção da disciplina de Sociologia pela lei 11.684 de 2008 até 2018, elaborados por Bodart e Silva-Sampaio (2019), apontam que o cenário quanto à entrada de professores com formação específica para lecionar na área alterou de 11,45\% para 12,5\%. Mesmo assim, segundo os autores, hoje temos mais docentes de Sociologia com formação em História (19,7\%) e em Licenciatura em Pedagogia (13,9\%) do que de docentes das áreas específica de licenciatura em Ciências Sociais (12,5\%).

Bodart e Silva-Sampaio (2019) demonstraram que além desse fator, a maior parte dos Estados introduziu somente uma hora aula semanal em cada ano do ensino médio, conforme o mínimo estabelecido na lei 11.684/08. Esse tem sido um fator que tem levado os docentes a lecionarem em quantidades de turmas acima da média dos professores das outras disciplinas, acarretando um aumento expressivo do trabalho extra a sala de aula, como 
preparação de aulas, de atividades, correção das avaliações. Observa-se ainda, que em muitos casos, os docentes trabalham em escolas diferentes. Essa questão apresenta-se como elemento importante da precarização do trabalho desses docentes e no comprometimento, em alguns casos, da qualidade do ensino. Somando-se a baixa carga horária destinada à disciplina de Sociologia com a falta de docentes para área, além do fato da disciplina ser deixada em segundo plano em várias instituições escolares e, às vezes, sendo oferecida como complemento de carga horária para os demais docentes das áreas afins, são fatores que podem, de certo modo, levar a um desestimulo de ingressantes ao ensino superior a cursarem a licenciatura nas Ciências Sociais.

A disciplina de Sociologia segue a lógica desse modelo apresentado acima. Ela representa um campo que luta para ser inserida e se manter nas estruturas do sistema educacional. Apresenta uma relação de disputa de poder, de projetos que se defendem dentro de uma concepção de sociedade como discutidas por Apple (2006) e Sacristán (2000).

Desse modo, pode-se dizer que todo currículo se materializa com base nos conhecimento que se tornam importantes para a formação de determinada parcela da população, definidos, de um lado, por uma parcela restrita de intelectuais que assumem posições de maior influência decisória no sistema educacional; na outra extremidade, por docentes que lecionam nas suas respectivas escolas. Entendemos que não há neutralidade nas ações da construção curricular, inclusive o que é definido para ser ensinado como conteúdo de Sociologia.

Nesse sentido, Sacristán (2000, p. 09) salienta que "a qualidade da educação e do ensino tem muito a ver com o tipo de cultura que nele se desenvolve, que obviamente ganha significado educativo através das práticas e dos códigos que a traduzem em processos de aprendizagem para os alunos”. Ele observa que as práticas escolares têm muito a ver com as tradições técnicas da cultura dominante de uma sociedade e que estão contidas no currículo dos seus sistemas educativos. Ainda faz uma crítica à forma como são elaboradas e tomadas as decisões sobre os currículos, pois essas decisões deveriam ser tomadas de forma diferente por quem de fato tem conhecimento sobre o assunto.

Os conteúdos da disciplina Sociologia, e as demais disciplinas que compõem a Educação Básica, estavam estabelecidos em documentos oficiais, como os Parâmetros Curriculares Nacionais para o Ensino Médio - PCNEM. Seguindo-os, o Estado de Minas Gerais estabeleceu os Currículos Básicos Comuns - CBCs, que tentam aproximar o texto mais amplo e genérico trazido pelo PCN para uma linguagem e situações mais próximas da cultura vivenciada nesse Estado.

Os Parâmetros Curriculares Nacionais foram definidos após a promulgação da Lei de Diretrizes e Bases na Educação - LDB, n9.394 de 1996. Um dos aspectos a considerar é que, naquele momento, estavam em jogo os poderes estabelecidos e já estruturados entre os campos de saber, representados pelas disciplinas, assim como um espaço de disputas entre projetos de sociedade, nos quais os grupos de poder exercem suas influências.

Miguel Arroyo (2013, p.77) salienta que, nesse processo, os conteúdos legitimados nas matrizes curriculares foram os mais fechados, mas, 
os saberes tidos como mais úteis ao mercado ocuparam os maiores tempos, foram prestigiados e seus docentes fizeram questão de prestigiá-los com os saberes mais nobres, mais exigentes. Nessa defesa se autoprestigiavam, como licenciados das áreas mais nobres. Os saberes duros, seletivos, porque úteis e fechados, passavam a ser os mais prestigiados. Criou-se uma cultura de qualidade para legitimá-los.

Em suas reflexões, destaca, ainda, o campo de força entre aqueles que foram marginalizados nesse processo de prestígio/desprestígio de determinadas disciplinas e, consequentemente, suas matrizes curriculares e os tempos destinados a elas:

Houve ainda pressões de profissionais de áreas que foram marginalizadas porque mais próximas da formação das capacidades abertas, para serem incorporadas como saberes tão legítimos. Sabemos que tem sido uma das tensões curriculares e profissionais complicadas, não resolvidas ainda. Por que a marginalização dos conteúdos de história, geografia, literatura, arte, cultura, sociologia, filosofia, estética, movimento, memória coletiva...? Porque foram marginalizados o ensino e o aprendizado de saberes e competências humanas mais abertos e desinteressados? (ARROYO, 2013, p.77).

\section{Educação de Jovens e Adultos: um campo secundarizado nas políticas educacionais}

Em países que universalizaram a educação básica, a educação de adultos é pensada como requalificação profissional, ou mesmo, como educação ao longo da vida, entretanto, no Brasil, e em boa parte da América Latina e do Caribe, a Educação de Jovens e Adultos é, ainda, entendida como alfabetização e escolarização, sendo fruto de sociedades profundamente desiguais (DI PIERRO, 2008). Enfrentamos, a luta pelo direito de 11 milhões de adolescentes, jovens, adultos e idosos dos grupos populares e, marcadamente negros/as, apropriarem-se da leitura e escrita, como bens sociais e coletivos, aos quais tem pleno direito como seres humanos, já elencados na Constituição Federal de 1988:

No processo de democratização do Brasil e no bojo das mobilizações em torno da elaboração da Constituição de 1988, a EJA adquire, pela primeira vez, o estatuto de direito público subjetivo, quando considerarmos o que foi previsto no artigo 205 que estabelece que a educação é, “direito de todos e dever do Estado e da família, será promovida e incentivada com a colaboração da sociedade, visando ao pleno desenvolvimento da pessoa, seu preparo para o exercício da cidadania e sua qualificação para o trabalho”. Como também, se atentarmos para o artigo 208, que define que o "ensino fundamental, obrigatório e gratuito, inclusive para os que a ele não tiveram acesso na idade própria” (BRASIL, 1988)

Em 1996, a LDB nº 9394 avança na tentativa de superação da concepção da educação dos jovens e adultos como suplência, criando, pela primeira vez, na legislação brasileira, no Capítulo II da Educação Básica, uma seção específica para a Educação de Jovens e Adultos. Por outro lado, mantém a previsão dos exames supletivos e reduz a idade para realização dos 
referidos exames de 18 para 15 anos no Ensino Fundamental e de 21 para 18 anos no Ensino Médio, provocando, nas décadas seguintes, uma reconfiguração do público da EJA, que passa a receber adolescentes de 15 a 17 anos, expulsos do ensino regular.

No decorrer da década de 1990, a EJA perde força e reconhecimento no contexto das políticas neoliberais empreendidas no país. Nessa década, intensificou-se um processo de desqualificação da EJA no âmbito das políticas públicas, provocando um retrocesso nas conquistas alcançadas nos últimos anos de luta pela inclusão da população jovem e adulta no direito à educação (HADDAD e XIMENES, 2018; DI PIERRO, JOIA e RIBEIRO, 2001).

O retrocesso no plano das políticas públicas exprimiu-se no quadro legal por meio de medidas restritivas tomadas em 1996, quando "uma emenda à Constituição suprimiu a obrigatoriedade do ensino fundamental aos jovens e adultos da EJA, mantendo apenas a garantia de sua oferta gratuita”. Desse modo, o artigo 208 da Constituição sofre uma mudança sutil, desobrigando o Estado de assumir uma ação convocatória e mobilizadora no campo da EJA (DI PIERRO, JOIA e RIBEIRO, 2001, p. 67).

Outra medida que impactou negativamente à educação dos jovens e adultos foi a aprovação da Lei do FUNDEF, em 1997, que deixou de fora as matrículas de EJA do cômputo dos cálculos para o financiamento, provocando um grave desinvestimento na sua oferta por parte dos Municípios e Estados da Federação, expresso no fechamento de escolas que oferecia esse nível de ensino em todo o país.

Em 2000, foram aprovadas as Diretrizes Curriculares Nacionais para a EJA, sendo, nesse documento, reafirmada como modalidade da Educação Básica no contexto das pressões sobre o poder público para incluir as matriculas da EJA no financiamento da Educação Fundamental que focara o atendimento a pessoas com idade de 7 aos 14 anos. Contudo, essa conquista somente acontecerá em 2007 com a aprovação da Lei do FUNDEB, que incluiu as matriculas de EJA no cômputo do financiamento, mesmo que com um fator de ponderação menor que os outros níveis e modalidades da Educação. Essa medida possibilitou uma ampliação da oferta da EJA escolar, no Ensino Fundamental e Médio, nas diferentes redes públicas de ensino no Brasil.

Segundo MUSIAL (2003, p. 38-39), as Diretrizes Curriculares Nacionais para a EJA falam

da necessidade de flexibilidade curricular, na qual as experiências que os alunos trazem consigo sejam aproveitadas pela escola, e que temas da vida cotidiana, a exemplo do trabalho, possam se tornar elementos geradores de um currículo pertinente.

E continua, afirmando que "ao considerar o trabalho como um componente curricular importante, as Diretrizes Curriculares destacam que, seja pela experiência, seja pela necessidade imediata de inserção profissional, o mesmo merece especial destaque”. Segundo o referido documento 
A busca da alfabetização ou da complementação de estudos participa de um projeto mais amplo de cidadania que propicie inserção profissional e busca de melhoria das condições de existência. Portanto, o tratamento dos conteúdos curriculares não pode se ausentar desta premissa fundamental, prévia e concomitante à presença em bancos escolares: a vivência do trabalho e a expectativa de melhoria de vida. Esta premissa é o contexto no qual se deve pensar e repensar o liame entre qualificação para o trabalho, educação escolar e os diferentes componentes curriculares. (BRASIL, 2000 p. 54-55)

Sendo uma modalidade da Educação Básica, é preciso considerar que a EJA é marcada pelo recorte de classe, de raça-etnia, de gênero de seus sujeitos, sendo também geracional e regional. Portanto, atende, na atualidade, um público diverso do ponto de vista de marcadores sociais, culturais e etários. Não é qualquer adolescente, jovem, adulto e idoso que é aluno da EJA. Como nos alerta Arroyo (2011, p.29), são jovens populares, que "fazem parte dos mesmos coletivos sociais, raciais, étnicos, culturais”. Possuem identidades coletivas marcadas pela negação de direitos, abandono social e exclusão.

Destacamos que, embora as décadas iniciais do século XXI tenham sido marcadas por conquistas nesse campo, como a inclusão da EJA no FUNDEB, a redução nos índices de analfabetismo em quase 10 pontos percentuais e a ampliação da escolaridade de alguns segmentos sociais, como as mulheres, "as características mais comumente associadas à EJA são, em grande parte, marcada pelo preconceito”, como ressaltam Galvão e Di Pierro (2013) e Sales e Paiva, (2014). Essa modalidade ainda é vista como "um lugar onde tudo é permitido: a improvisação, o amadorismo, o trabalho realizado de qualquer jeito, com qualquer material e pessoas que tenham boa vontade para ministrar aulas para outras” consideradas 'destituídas de saberes'. (MUSIAL et. al., 2019, p.41)

Nesse sentido, alguns desafios nessa área educacional continuaram presentes, entre eles, a oferta de alfabetização deslocada da escolarização, sendo realizada por pessoas com precária formação e remuneração, a insuficiente oportunidade de formação de professores para a Educação de Jovens e Adultos e a oferta dessa modalidade de ensino em programas, governamentais importantes, mas muitos deles desconectados entre si, pois pulverizados em diferentes Ministérios e Secretarias, a reduzida oferta do EJA no Ensino Médio.

Desde 2007, a EJA vem apresentando uma considerável redução de número de matrículas e fechamento de salas de aula e escolas em praticamente todo o território nacional. Isso não seria problema, se não tivéssemos um cenário ainda de baixa escolaridade e uma população de 11 milhões de brasileiros não alfabetizados (DI PIERRO, HADDAD, 2015).

Considerada como um direito público e subjetivo e como responsabilidade pública, desde a Constituição de 1988, a Educação de Jovens e Adultos tem uma história marcada por processos de negação, desqualificação e secundarização nas políticas públicas, ausência de formação de professores especializados, oferta irregular e descontínua de processos de alfabetização e escolarização. Além disso, é profundamente sensível aos momentos de autoritarismo, de crise econômica e social, sofrendo, em primeira mão, as restrições orçamentárias e, consequentemente, recuo das políticas educacionais pensadas para essa 
parcela da população. Acompanha, de forma dramática, o movimento de avanços e recuos identificado por Cury (2014), ao analisar a relação entre direito e direito à educação nas Constituições brasileiras, no qual em momentos de autoritarismo esses direitos são restringidos, especialmente, pela redução ou retirada do seu financiamento ou pelo controle ideológico de suas propostas e práticas.

\section{Análise da regulamentação da EJA na rede estadual de ensino de Minas Gerais nos anos 2012-2016}

Em momento posterior ao da promulgação da Lei 11.684/2008, foi implementada a Educação de Jovens e Adultos - EJA - na rede estadual de educação em Minas Gerais, conforme publicado na Resolução nº 2197 de 2012 da Secretaria de Estado da Educação daquele Estado. A Educação de Jovens e Adultos foi assim definida:

Art. 38 A Educação de Jovens e Adultos - EJA - destina-se àqueles que não tiveram acesso ou continuidade de estudos no Ensino Fundamental e Médio na idade própria. [...]

Art. 40 Os cursos presenciais da EJA poderão ser oferecidos nas Escolas Estaduais, para atendimento àdemanda efetivamente comprovada, após aprovação desta Secretaria, e terão a seguinte organização:

I - curso presencial dos anos finais do Ensino Fundamental, com duração de 02 (dois) anos letivos, organizados em 04(quatro) períodos semestrais; II - curso presencial do Ensino Médio, com duração de 01 (um) ano e meio, organizado em 03 (três) períodos semestrais.

Parágrafo único. A nova organização dos cursos presenciais de EJA será implantada, gradativamente, a partir do ano de 2013. [...]. (MINAS GERAIS, 2012, p.6-7).

Em Minas Gerais, a Resolução n 2.197, de 26 de outubro de 2012, da Secretaria de Estado da Educação, passa a regulamentar, a partir de 2013, para toda rede estadual, a modalidade da Educação de Jovens e Adultos na sua forma presencial. Assim, ela inclui a modalidade presencial às formas já ofertadas anteriormente, como a semipresencial, como estabelece o formato de funcionamento dos Centros Estaduais de Educação Continuada CESEC e os Postos de Educação Continuada - PECON, conforme os artigos a seguir:

Art. 41- Os Centros Estaduais de Educação Continuada - CESEC - e os Postos de Educação Continuada - PECON - oferecem cursos com momentos presenciais e não presenciais de Educação de Jovens e Adultos - anos finais do Ensino Fundamental, Ensino Médio e de Educação Profissional.

Parágrafo único. Os cursos de Educação Básica oferecidos pelo CESEC são desenvolvidos em regime didático de matrícula por disciplina ou conjunto de disciplinas, a qualquer época do ano, sendo que sua organização, estrutura e funcionamento incluem momentos presenciais e não presenciais, sem frequência obrigatória (MINAS GERAIS, 2012, p. 8-9, grifos nossos). 
Fazendo uma análise desse documento, podemos elaborar algumas hipóteses, as quais serão abordadas a seguir. Em um primeiro momento, a Resolução SEE-MG 2197/2012 estabelece as bases de funcionamento da Educação de Jovens e Adultos em Minas Gerais. Ela apresenta um papel de uniformização quanto à institucionalização da sua oferta e de diversificação dessa modalidade de ensino pelas escolas estaduais de ensino presencial. É importante destacar que a EJA já era prevista e oferecida na forma de semipresencial, ou os chamados “momentos presenciais e não presenciais” nos Centros Estaduais de Educação Continuada - CESEC e os Postos de Educação Continuada - PECON.

Em um segundo momento, a Resolução SEE N ${ }^{\circ}$ 2.843, de 13 de janeiro de 2016, vem reafirmar, nos artigos $1^{\circ}, 2^{\circ}$ e $3^{\circ}$ aos artigos $40^{\circ}$ e $41^{\circ}$ da Resolução $2.197 / 2012$, que estabelecem a oferta da EJA no formato presencial em toda rede estadual:

A SECRETÁRIA DE ESTADO DE EDUCAÇÃO DE MINAS GERAIS, no uso de sua competência, tendo em vista o disposto na Lei Federal n ${ }^{\circ}$ 9.394, de 20 de dezembro de 1996, na Resolução CNE/CEB n ${ }^{\circ} 1$, de 05 de julho de 2000, na Resolução CNE/CEB n ${ }^{\circ}$ 03, de 15 de junho de 2010, no Parecer CNE/CEB n ${ }^{\circ} 11$, de 10 de maio de 2000, no Parecer CNE/CEB nº 6, de 07 de abril de 2010, e na Resolução SEE $n^{\circ}$ 2.197, de 26 de outubro de 2012, e considerando:

- O diálogo promovido com a comunidade escolar durante a Virada Educação; - o diálogo promovido com os estudantes e profissionais da educação durante as Rodas de Conversas realizadas nos Territórios de Desenvolvimento;

- as reflexões promovidas pelo Grupo de Trabalho constituído para analisar e discutir o Ensino Médio; e - as sugestões advindas dos encontros de formação do Pacto Nacional pelo Fortalecimento do Ensino Médio. RESOLVE:

Art. $1^{\circ}$ A Educação de Jovens e Adultos/EJA - cursos presenciais, modalidade da Educação Básica ofertada nas escolas da rede pública estadual de Minas Gerais, destina-se àqueles que não tiveram acesso ou continuidade de estudos no Ensino Fundamental e Médio na idade de direito.

[...]

Art. $4^{\circ}$ A proposta curricular da Educação de Jovens e Adultos/EJA deverá observar o número de módulos-aula e a carga horária definidos nos Anexos I, II e III.

\$1 - A carga horária diária da Educação de Jovens e Adultos noturno será de 4 (quatro) módulos de 45 (quarenta e cinco) minutos. (MINAS GERAIS, 2016, p.1, grifos nossos).

Analisando o documento, ele cita os momentos de diálogos (nos grifos) que aconteceram antes de estabelecer a Resolução sobre a regulamentação da Educação de Jovens e Adultos presencial $^{6}$. Comparando essa nova regulamentação da Resolução SEE $N^{o} 2.843$, de 13 de janeiro de 2016, com a Resolução SEE n 2.197, de 26 de outubro de 2012, uma das mudanças na estrutura do funcionamento está na carga horária, que passa de 50 minutos a hora-aula para 45 minutos, como no parágrafo $1^{\circ}$ do art. $4^{\circ}$ da Resolução SEE n 2.843/2016. 
No momento da pesquisa, esse era um cenário muito recente, pois houve a troca de governo estadual, ocorrida a partir do início de 2015. A nova gestão emanou a Resolução SEE $n^{\circ} 2.843$, de 13 de janeiro de 2016, já com algumas mudanças no formato da EJA, como a forma de construção, mediante diálogos em espaços estabelecidos, como a "Virada da Educação”, “Grupos de Trabalho”, assim como as "sugestões advindas dos encontros de formação do Pacto Nacional pelo Fortalecimento do Ensino Médio”, como pode ser observado no excerto citado acima dessa Resolução, que dispõe sobre a organização e o funcionamento da Educação de Jovens e Adultos/EJA em cursos presenciais, nas escolas da Rede Pública Estadual de Minas Gerais.

Um dos aspectos que tem marcado os programas/políticas para Educação de Jovens e Adultos na Rede Estadual do Estado de Minas Gerais são as várias mudanças, ocorridas com bastante frequência, o que evidencia o caráter assumido como programa de governo e não como uma política de Estado ${ }^{7}$, que tenha conseguido transcender as gestões de governos.

Um aspecto que podemos levantar é o desprestígio ocupado pela EJA, que se constitui um dos graves problemas enfrentados na afirmação da modalidade e, consequentemente, como política pública, sem que houvesse um financiamento que garantisse a sua viabilidade. Quer dizer,

No Brasil, como em quase toda a América Latina, a educação de jovens e adultos ocupou, no desenvolvimento do sistema de ensino público, um papel subsidiário às demais modalidades, cumprindo função compensatória de reposição de escolaridade não realizada na idade considerada apropriada, ou de aceleração de estudos de pessoas com atraso escolar. O desprestígio da educação de jovens e adultos repercutiu no escasso financiamento, na precariedade institucional e na posição desfavorável ocupada pelos seus órgãos de gestão na hierarquia governamental (DI PIERRO, 2008, p.397).

Essa análise feita por Di Pierro (2008) pode ser estendida para a situação da EJA em Minas Gerais. Os programas semipresenciais de Educação de Jovens e Adultos, como estabelecidos pelo funcionamento dos Centros Estaduais de Educação Continuada - CESEC e os Postos de Educação Continuada - PECON, hoje se apresentam como as principais formas de acesso à EJA em Minas Gerais. Essas estruturas, prevendo uma educação semipresencial, sendo a maior parte à distância, conta com um efetivo de docentes e demais servidores insuficientes ao previsto para as escolas que oferecem a modalidade de EJA presencial, conforme consta no anexo III da Resolução SEE n ${ }^{\circ}$ 2836, de 28 de dezembro de 2015, "que Estabelece normas para a organização do Quadro de Pessoal das Escolas Estaduais e a designação para o exercício de função pública na Rede Estadual de Educação Básica no ano de 2016 e dá outras providências”. (MINAS GERAIS, 2015).

Assim, os dados trazidos neste trabalho podem ajudar pensar nas dificuldades de analisar os efeitos produzidos, até então, pela inclusão da disciplina de Sociologia na Educação de Jovens e Adultos na REE-MG, discutida a seguir. 


\section{A institucionalização do ensino da Sociologia e da EJA presencial em Minas Gerais}

O processo de institucionalização do ensino da Sociologia na EJA insere-se no período histórico recente da educação brasileira e da educação do Estado de Minas Gerais, que sofreram mudanças consideráveis tanto no ensino da disciplina de Sociologia quanto na modalidade de Educação de Jovens e Adultos na sua oferta presencial. No ano de 2008, após um longo período de luta de vários setores da sociedade civil, como associações de sociólogos, sindicatos dos docentes de Sociologia e Filosofia, foi instituída a obrigatoriedade de ambas as disciplinas nos currículos do ensino médio por força da Lei 11.684 de 2 de junho de 2008.

Essa alteração passou a vigorar a partir da publicação da referida lei, provocando mudanças em todo sistema de ensino, assim como nos cursos de licenciaturas de ambas as áreas, que passaram a ter espaço ampliado de atuação profissional dos seus egressos.

Não se pode negar que, na última década, houve algum avanço ${ }^{9}$, tratando-se do campo da disciplina de Sociologia, representado pela luta pela implementação da Sociologia e da Filosofia como disciplinas obrigatórias no Ensino Médio. Porém, pode-se considerar como sendo um progresso limitado, pois não parte de uma mudança de concepção, ou seja, um debate sobre o tipo de projeto de educação e currículo se deseja para a sociedade brasileira. Ele se apresenta, por um lado, estabelecendo ainda mais tensão nesse campo, visto que acaba por repartir e inserir mais duas disciplinas em uma matriz curricular obrigatória e extremamente engessada por uma concepção disciplinar de currículo que hierarquiza os campos do conhecimento e dificulta o trabalho pedagógico que ultrapasse as fronteiras disciplinares/fragmentadas. Esse fato gerou e ainda acarreta tensões também entre os docentes, pois, para a inserção das disciplinas de Filosofia e Sociologia, houve a diminuição da quantidade de horas-aula em outras disciplinas, já que a lei estabelece que as mesmas devam ter, no mínimo, 1 hora-aula semanal em todos os anos do ensino médio.

\section{Considerações finais}

Nesse artigo, analisamos os desafios enfrentados por duas áreas de conhecimento e dois campos de formação, quais sejam: a Sociologia e a Educação de Jovens e Adultos. Com experiências e trajetórias distintas, apresentam-se como campos, na perspectiva bourdiesiana, como espaço de disputa por legitimidade e reconhecimento nas políticas educacionais e curriculares.

Em primeiro lugar, constatou-se um processo heterogêneo de luta pela inserção da disciplina de Sociologia e de Filosofia no Brasil, onde em cada Estado, adquiriu contornos diferentes, culminando na aprovação da Lei Federal n 11.684/2008, colocando ambas como obrigatórias no currículo do Ensino Médio. Esse processo foi importante para a reafirmação da disciplina de Sociologia nos sistemas de ensino, porém, a partir da aprovação da Lei 
13.415/2017 da reforma do ensino médio, essas conquistas encontram-se ameaçadas, pois esse referido texto legal retira a obrigatoriedade das referidas disciplinas.

Em segundo, sobre a produção dos efeitos esperados pela disciplina de Sociologia debatida a partir de Chervel (1990), novamente foram prejudicados, pois a insegurança jurídica de todos os atores envolvidos, além da não existência das garantias da continuidade da implementação da disciplina, acarreta prejuízos de análises e mensuração quanto a eficácia produzida pela mesma, e os espaços de trabalho para os egressos dessa área de Sociologia.

No terceiro momento deste trabalho, buscamos estabelecer um debate sobre o lugar das disciplinas de Sociologia, a partir da teoria crítica do currículo de Sacristán (2000), Apple (2006) com os conceitos de prestígio/desprestígios das disciplinas, a partir dos ditames da cultura dominante do mercado, que acaba por escolher quais conteúdos a ser considerados para formação no atendimento ao “mercado”, citado por Miguel Arroyo (2013). Nessa perspectiva, concluímos que a disciplina de Sociologia se apresenta no rol das disciplinas desprestigiadas, representada pela natureza teórico-conceitual, mais articulada á formação para a cidadania do que para o mercado. Esse desprestígio se traduz, também, pelos tempos de aula atribuídos à disciplina nas matrizes curriculares.

E por último, indicamos que, sendo o currículo um campo de disputa, a disciplina de Sociologia tem ocupado um lugar provisório, sempre questionado em alguns momentos político-sociais e defendido em outros. Quando analisamos o ensino de Sociologia na modalidade Educação de Jovens e Adultos, campo marcado pela provisoriedade e descontinuidade de suas políticas e programas, a possibilidade de produção de efeitos se torna ainda mais problemática. Pois, mesmo com a obrigatoriedade do ensino de Sociologia na Educação Básica, não se produziu as condições necessárias para a sua oferta qualificada, nem aumento substancial da quantidade de licenciados nas redes de ensino. Quanto ao ensino de Sociologia na Educação de Jovens e Adultos, essa enfrenta um duplo desafio, se estabelecer como campo legítimo em uma modalidade que ocupa lugar marginal e transitório nas Políticas Educacionais.

\section{Notas}

1. [...] O processo de impeachment de Dilma Rousseff teve início em 2 de dezembro de 2015, quando o ex-presidente da Câmara dos Deputados, Eduardo Cunha, deu prosseguimento ao pedido dos juristas Hélio Bicudo, Miguel Reale Júnior e deputada Janaína Paschoal. Com uma duração de 273 dias, o caso se encerrou em 31 de agosto de 2016, tendo como resultado a cassação do mandato, mas sem a perda dos direitos políticos de Dilma. [...] No terceiro dia do julgamento, a presidente Dilma compareceu ao Congresso para se defender e negou ter cometido os crimes de responsabilidade de que foi acusada. Dilma classificou de golpe a aprovação do impeachment e acusou o então vice-presidente, Michel Temer, e o ex-presidente da Câmara, Eduardo Cunha, de conspiração. Após 6 dias de julgamento, o Senado concluiu, em 31 de agosto, o impeachment de Dilma Rousseff, cassando o mandato da presidente, mas mantendo os seus direitos políticos. Foram 61 votos favoráveis e 20 contrários no julgamento que ficará marcado na história do Congresso Nacional e do Brasil. Disponível em: <http://www12.senado.leg.br/noticias/materias/2016/12/28/impeachment-dedilma-rousseff-marca-ano-de-2016-no-congresso-e-no-brasil > . Acesso em: 20 mar. 2017

2. A presidenta Dilma Rousseff foi eleita pelo Partido dos Trabalhadores (PT) em 2010 e reeleita em 2014. Estava cumprindo a quarta legislatura do PT na Presidência da República. 
3. Esse movimento se deu via articulação de Michel Temer e seu respectivo grupo político com elites empresariais da indústria, como a Federação das Indústrias do Estado de São Paulo - FIESP, de parcela das redes de televisão de sinal aberto, como a Rede Globo, além de alguns partidos políticos que, até antes do processo de impeachment, apresentavamse nesse cenário político como oposição, como PSDB, DEM, entre outros. A partir desse novo cenário político, houve mudanças significativas nos rumos das políticas educacionais no Brasil.

4. A Lei Federal $n^{\circ} .13 .415$, de 16 de fevereiro de 2017, intitulada de "Reforma do Ensino Médio" suprimiu a obrigatoriedade da disciplina de Sociologia no Ensino Médio.

5. Nesse período, do final da década de 1990, após a aprovação da Lei de Diretrizes e Bases em 1996, iniciaram a produção dos Parâmetros Curriculares Nacionais - PCNs e das Diretrizes Curriculares Nacionais - DCNs. Mesmo com os conteúdos de Sociologia presentes nos PCNs de 1998, as DCNEMs desse mesmo ano, trazia que a disciplina de Sociologia deveria aparecer de forma transversal, tendo seus conteúdos diluídos entre as demais disciplinas, como podemos observar na RESOLUÇÃO CEB Nº 3, DE 26 DE JUNHO DE 1998 que Institui as Diretrizes Curriculares Nacionais para o Ensino Médio, trouxe no seu artigo 10, no parágrafo $2^{\circ}$ : As propostas pedagógicas das escolas deverão assegurar tratamento interdisciplinar e contextualizado para: a) Educação Física e Arte, como componentes curriculares obrigatórios; b) Conhecimentos de filosofia e sociologia necessários ao exercício da cidadania. Não consta neste documento a obrigatoriedade dos conteúdos de Filosofia e Sociologia. Dessa forma, diversos Estados interpretaram que não haveria a necessidade de criar uma disciplina exclusiva, e, somente garantir a presença dos conteúdos delas dentro de outras disciplinas.

6. Vale ressaltar que esses diálogos aconteceram durante a gestão do Governandor Fernando Pimentel, do Partido dos Trabalhadores que, embora repleto de contradições, possibilitou alguns espaços de diálogo com a comunidade.

7. Em Notas sobre a redefinição da identidade e das políticas públicas de educação de jovens e adultos no Brasil, Maria Clara Di Pierro traz, como pontos sobre a precariedade da EJA, “As dificuldades de instituição e consolidação de espaços de formação decorrem de múltiplos fatores, como a persistência da visão equivocada que concebe a educação de jovens e adultos como território provisório sempre aberto à improvisação” (DI PIERRO, 2005, p.1132).

8. A realização do primeiro concurso da Rede Estadual de Educação de Minas Gerais para docentes licenciados em Ciências Sociais/Sociologia no ano de 2011.

\section{Referências}

APPLE, M. Ideologia e Currículo. Tradução Vinícius Figueira. 3. ed. Porto Alegre: Artmed, 2006.

ARROYO, M. G. Educação de jovens e adultos: um campo de direito e de responsabilidade pública. In. SOARES, Leôncio, GIOVANETTI, Maria Amélia, GOMES, Nilma Lino (Orgs.). Diálogos na Educação de Adultos. Belo Horizonte: Autêntica, 2011. p. 19-50.

ARROYO, M. G.. Ofício de Mestre: Imagens e Autoimagens. 14. ed. Petrópolis, Rio de Janeiro: Vozes, 2013. BODART, Cristiano das Neves; SAMPAIO-SILVA, Roniel. Capítulo 2 Quem leciona sociologia após 10 anos de presença no ensino médio brasileiro?. In: BODART, Cristiano das Neves; LIMA, Wanderson Luan dos Santos. (Orgs.) O ensino de Sociologia no Brasil, vol.1. Maceió: Editora Café com Sociologia, 2019. p.3358

BOURDIEU, P. Razões práticas: Sobre a teoria da ação. Tradução de Mariza Correa. Campinas, São Paulo: Papirus. 1996.

BOURDIEU, P. Escritos da Educação. Maria Alice Nogueira; Afranio Catani (Orgs.) 15. ed. Petrópolis, Rio de Janeiro :Vozes, 2014.

BRASIL, Constituição da República Federativa do Brasil: Diário Oficial da União. 5 de outubro de 1988.Disponível em:< https://www2.senado.leg.br/bdsf/bitstream/handle/id/518231/CF88_Livro_EC91_2016.pdf>. Acesso em 10 de nov. de 2019.

BRASIL. Lei n. 9.394, de 20 dez. 1996. Estabelece a Lei de Diretrizes e Bases da Educação Nacional. Brasília, 1996. Diário Oficial da União, Brasília, 23 dez.1996. 
BRASIL. Ministério da Educação. Conselho Nacional de Educação. Câmara de Educação Básica. Resolução $\mathrm{CEB} \mathrm{n}^{\circ}$ 3, de 26 de junho de 1998. Institui as Diretrizes Curriculares Nacionais para o Ensino Médio. Diário Oficial da União, Brasília, DF, 5 ago. 1998

BRASIL. Lei n. 11.684 de 02 de jun. 2008. Altera o art. 36 da Lei n-0 9.394, de 20 de dezembro de 1996, que estabelece as diretrizes e bases da educação nacional, para incluir a Filosofia e a Sociologia como disciplinas obrigatórias nos currículos do ensino médio. Diário Oficial da União, Brasília, 3 jun. 2008.

BRASIL. Ministério da Educação. Conselho Nacional de Educação/Câmara de Educação Básica. Diretrizes curriculares nacionais para a educação de jovens e adultos. Parecer CEB 11/2000a. Relator: Carlos Roberto Jamil Cury. 10 de maio de 2000. Disponível em: http://confinteabrasilmais6.mec.gov.br/images/documentos/parecer_CNE_CEB_11_2000.pdf. Acesso em: 12.11.2019.

CHERVEL, A. História das disciplinas escolares: reflexões sobre um campo de pesquisa. Teoria e Educação, Porto Alegre, n. 2. p.177-229, 1990.

CURY, C. R. J.. Educação e direito à educação no Brasil: um histórico pelas constituições. Belo Horizonte: Mazza Edições, 2014.

DI PIERRO, M. C. Notas sobre a redefinição da identidade e das políticas públicas de educação de jovens e adultos no Brasil. Educ. Soc. Campinas, v. 26, n. 92, p. 1115-1139, Especial, out. 2005. Disponível em: $<$ http://www.cedes.unicamp.br> Acesso em: 03 mar. 2016.

DI PIERRO, M. C. Educação de Adultos na América Latina e no Caribe: Trajetórias recentes. Cadernos de Pesquisa - Fundação Carlos Chagas, v. 38, n. 134, p. 367-391, maio/ago. 2008. Disponível em:> http://www.scielo.br/pdf/cp/v38n134/a0638134.pdf>. Acesso em: 04 mar. 2016.

DI PIERRO, M. C. Luta social e reconhecimento jurídico do Direito Humano dos jovens e adultos à educação. Revista Educação (UFSM), v. 33, $\mathrm{n}^{\circ}$ 3, p.395-410, set./dez. 2008. Disponível em: $<$ http://cascavel.ufsm.br/revistas/ojs-2.2.2/index.php/reveducacao/article/viewFile/1617/911>. Acesso em: 01 mar. 2016.

DI PIERRO, M. C.. A Educação de Jovens e Adultos no Plano Nacional de Educação: Avaliação, Desafios e Perspectivas. Educ. Soc. Campinas, v. 31, n 112, p. 939-959, jul./set. 2010. Disponível em: $<$ http://www.scielo.br/pdf/es/v31n112/15.pdf > . Acesso em: 02 mar. 2016.

DI PIERRO, Maria Clara, JOIA, Orlando, RIBEIRO, Vera Masagão. Visões da educação de jovens e adultos no Brasil. Cadernos Cedes, ano XXI, $\mathrm{n}^{\circ}$ 55, novembro/2001. Disponível em: http://www.scielo.br/pdf/ccedes/v21n55/5541. Acesso em 02 mar. 2016.

DI PIERRO, Maria Clara, HADDAD, Sérgio. Transformações nas políticas de educação de jovens e adultos no Brasil no início do terceiro milênio: uma análise das agendas nacional e internacional. Cadernos Cedes, Campinas, v. 35, n. 96, p. 197-217, maio-ago. 2015. Disponível em: http://www.scielo.br/pdf/ccedes/v35n96/1678-7110-ccedes-35-96-00197.pdf. Acesso em: 02 mar. 2016.

FERNANDES, Otair; PONTE JARDIM, Antônio. O Retorno da Sociologia no Rio de Janeiro: Uma luta que merece ser 2008.20 pautada. <www.labes.fe.ufrj.br/download/?ch=d73562f6a37be4770d678df250b99dcc> Acesso em: 13 set. 2016.

GALVÃO, Ana Maria de Oliveira; DI PIERRO, Maria Clara. Preconceito contra o analfabeto. 2. ed. São Paulo: Cortez, 2013.

HADDAD, S. A educação de Jovens e Adultos na LDB: um olhar passados 20 anos. In. BRZEZINSKI, Iria (Org.). LDB 1996 vinte anos depois: projetos educacionais em disputa. São Paulo: Cortez, 2018. p. 237260.

HADDAD, Sérgio; XIMENES, Salomão. A Educação de Pessoas Jovens e Adultas na LDB um olhar passados 20 anos. In. Brzezinski, Iria. LDB 1996 vinte anos depois: projetos educacionais em disputa. 1ed., São Paulo: Cortez, 2018. p. 237-260 
MEUCCI, S. A institucionalização da Sociologia no Brasil: os primeiros manuais e cursos. Dissertação (Mestrado em Sociologia) - Instituto de Filosofia e Ciências Humanas, Universidade Estadual de Campinas, Campinas, 2000. $157 \mathrm{fl}$.

MINAS GERAIS. Secretaria de Estado da Educação. Resolução nº 2179 de 26 de outubro de 2012. Dispõe sobre a organização e o funcionamento do ensino nas Escolas Estaduais de Educação Básica de Minas Gerais e dá outras providências. Minas Gerais - Órgão oficial dos poderes do Estado. Belo Horizonte: Imprensa Oficial Minas Gerais, 27 de out. 2012. p.65-67.

MINAS GERAIS. Secretaria de Estado da Educação. Resolução nº 2836 de 28 de dezembro de 2015. Estabelece normas para a organização do Quadro de Pessoal das Escolas Estaduais e a designação para o exercício de função pública na Rede Estadual de Educação Básica no ano de 2016 e dá outras providências. Minas Gerais. Órgão oficial dos poderes do Estado. Belo Horizonte: Imprensa Oficial Minas Gerais, 16 jan. 2016. p. 06-18.

MINAS GERAIS. Secretaria de Estado da Educação. Resolução n 2843 de 13 de janeiro de 2016. Dispõe sobre a Organização e o Funcionamento da Educação de Jovens e Adultos/EJA - cursos presenciais, nas escolas da rede pública estadual de Minas Gerais. Minas Gerais. Órgão oficial dos poderes do Estado. Belo Horizonte: Imprensa Oficial Minas Gerais, 14 jan. 2016. p.33-34.

MORAES, A. C. Ensino de Sociologia: periodização e campanha pela obrigatoriedade. Cadernos Cedes, v. 31, n. 85, p. 359-382, 2011.

MUSIAL, Gilvanice B. da S. A temática trabalho na educação de jovens e adultos: um estudo de caso de uma sala de aula de uma escola da Rede Municipal de Educação de Belo Horizonte - RME/BH. Dissertação (Mestrado). Centro Federal de Educação Tecnológica de Minas Gerais - CEFET-MG/DPPG, Belo Horizonte, 2002. 153p.

MUSIAL, Gilvanice B. da S., ALVES, Rejane O., SIQUEIRA, Sandra M. M., CARVALHOI, Marize, MATOS, Uilma R. de. Educação de jovens e Adultos: concepções, avaliações e políticas públicas no contexto do município de Salvador -Ba. In. PAIVA, Jane (Org.). Aprendizados ao longo da vida: sujeitos, políticas e processos educativos. Rio de Janeiro: EdUERJ, 2019. 228 p.

OLIVEIRA, A. Sentidos e dilemas do ensino de sociologia: um olhar sociológico. Revista Inter-legere, n. 9, 2011.

ROMANELli, Otaíza de O. História da Educação no Brasil (1930-1973). 17 ed., Petrópolis, Rio de Janeiro: Vozes, 1995.

SALES, Sandra R., PAIVA, Jane. As muitas invenções da EJA. Revista AAPE EEPA, v.22, n.58, jun.2014.

SACRISTÁN, J. G. O currículo: uma reflexão sobre a prática. Tradução Ernani F. Da F. Rosa. 3. ed. Porto Alegre: Artmed, 2000.

SILVA, I. L. F. Das fronteiras entre ciência e educação escolar: as configurações do ensino das Ciências Sociais/Sociologia no Estado do Paraná (1970-2002). 2006. Tese (doutorado). Faculdade de Filosofia, Letras e Ciências Humanas, Universidade de São Paulo, São Paulo, 2006. 312 fl. 


\section{Correspondência}

Edgar Gomes Junior: Professor do Instituto Federal do Norte de Minas Gerais - IFNMG E-mail: egmoesjunior@gmail.com

Gilvanive Barbosa da Silva Musial: Professora da Universidade Federal da Bahia E-mail: gilvanice.musial@ufba.br

Texto publicado em Currículo sem Fronteiras com autorização dos autores. 